\title{
ERRATUM
}

Thomas Gerloff

\section{Impact of genetic polymorphisms in transmembrane carrier-systems on drug and xenobiotic distribution}

Published online: 10 December 2003

(C) Springer-Verlag 2003

\section{Naunyn-Schmiedeberg's Arch Pharmacol (2003) DOI 10.1007/s00210-003-0813-5}

Throughout the review, the numbers and letters used to designate ABC-transporters follow the Transport Protein Database classification system as maintained by the Saier Laboratory Bioinformatics Group. They do not represent gene symbols. For this reason, SLC\# should instead read TC\#. Accordingly, MDR1 (ABCB1), for instance, is correctly designated as TC3A1.201.1.

The online version of the original article can be found at http://dx.doi.org/10.1007/s00210-003-0813-5

T. Gerloff ( $\bowtie)$

Institute of Clinical Pharmacology,

Charité University Medical Center, Humboldt University,

Schumannstrasse 20/21, 10098 Berlin, Germany

Tel.: +49-30-450525004, Fax: +49-30-450525933,

e-mail: thomas.gerloff@gmx.de 